\title{
The effect of metabolic syndrome and its components in midpregnancy on neonatal outcomes
}

\author{
Hadis Sourinejad ${ }^{1}$, Arezoo Shayan ${ }^{2}$, Shiva Niyati $^{1}$, Lida Moghaddam-Banaem*1
}

Received: 31 Dec 2017

Published: 23 Dec 2019

\section{Abstract}

Background: The prevalence of metabolic syndrome has been rising worldwide in recent decades. Determining the associations between metabolic syndrome and its components in midpregnancy with neonatal anthropometric indices and outcomes is a major challenge in both public health and clinical care.

Methods: This prospective cohort study was performed on 238 pregnant women at 24-28 weeks of gestation. Metabolic syndrome was recognized with 3 or more of the following criteria: triglyceride $\geq 247 \mathrm{mg} / \mathrm{dL}$; HDL $<61 \mathrm{mg} / \mathrm{dL}$; GCT $\geq 140 \mathrm{mg} / \mathrm{dL}$; prepregnancy body mass index $\geq 30 \mathrm{~kg} / \mathrm{m} 2$; and blood pressure $\geq 130 / 85 \mathrm{mmHg}$. Statistical analysis was performed through descriptive statistics, including mean, standard deviation, frequency, and percentage, Mann-Whitney test, Chi-square test, Fisher's exact test, linear and logistic regression in SPSS 21.0. P values $<0.05$ were considered significant.

Results: There was a significant association between blood hypertriglyceridemia in weeks 24-28 and anthropometric indices, including weight, height, and jaundice, in the first 24 hours of birth. Metabolic syndrome also had a significant relationship with jaundice $(\mathrm{P}=0.002)$. The results of linear regression analysis revealed that metabolic syndrome was positively associated with birth weight $(\mathrm{B}=0.18, \mathrm{P}=0.003)$ and height $(\mathrm{B}=0.18, \mathrm{P}=0.009)$. Among the components of metabolic syndrome, the results showed a direct relationship between increased blood triglyceride of the mother and newborn's weight $(\mathrm{B}=0.11, \mathrm{P}=0.011)$ and height $(\mathrm{B}=0.14$, $\mathrm{P}=0.007)$. Also, increased $\mathrm{BMI}$ had a significant direct relationship with the newborn's weight $(\mathrm{B}=0.11, \mathrm{P}=0.023)$ and height $(\mathrm{B}=0.12$, $\mathrm{P}=0.023)$. Moreover, decreased HDL had a significant reverse relationship with the newborn's weight $(\mathrm{B}=0.09, \mathrm{P}=0.042)$.

Conclusion: Presence of metabolic syndrome and its components in midpregnancy may influence neonatal outcomes, especially anthropometric indices. However, more studies should be conducted to further investigate these relationships.

Keywords: Pregnancy, Metabolic syndrome, Glucose challenge test, Neonatal outcomes, Neonatal anthropometric indices

Conflicts of Interest: None declared

Funding: The Faculty of Medical Sciences of Tarbiat Modares University funded this research.

\section{*This work has been published under CC BY-NC-SA 1.0 license.}

Copyright $\odot$ Iran University of Medical Sciences

Cite this article as: Sourinejad H, Shayan A, Niyati Sh, Moghaddam-Banaem L. The effect of metabolic syndrome and its components in midpregnancy on neonatal outcomes. Med J Islam Repub Iran. 2019 (23 Dec);33:147. https://doi.org/10.47176/mjiri.33.147

\section{Introduction}

Metabolic syndrome (MetS) consists of a set of risk factors for cardiovascular diseases, including hypertension,

Corresponding author: Dr Lida Moghaddam-Banaem,moghaddamb@modares.ac.ir

1. Department of Reproductive Health and Midwifery, Faculty of Medical Science, Tarbiat Modares University, Tehran, Iran

2. Departmnt of Midwifery, Fauclty Nursing and Midwifery, Hamadan University of Medical Sciences, Hamadan, Iran lipid disorders, increased blood sugar, and abdominal obesity. The incidence of the metabolic syndrome is high and

$\uparrow$ What is "already known" in this topic:

It is widely well known that metabolic syndrome is a multiple risk factor for cardiovascular and metabolic diseases. Normal pregnancy is considered a temporary attack on the metabolic syndrome, and it has been suggested that pregnancy may be a good stress test for carbohydrates, lipids, and vascular physiology. Cognition of the metabolic syndrome during pregnancy can help identify a subgroup of neonates exposed to this syndrome during fetal development.

$\rightarrow$ What this article adds:

The results of this study indicated that presence of metabolic syndrome and its components in midpregnancy may influence neonatal outcomes, particularly anthropometric indices. Therefore, attention to metabolic syndrome and its components can improve pregnancy and neonatal outcomes. 
increasing (1). The prevalence of MetS has been rising worldwide in rec ent decades, and it is a major challenge in both public health and clinical care (2). In the presence of this syndrome, the incidence risk of ischemic cardiovascular diseases and diabetes mellitus increases 2 and 5 times, respectively (3). MetS in its today's form was first proposed in Diabetes Journal by Reaven et al in 1988 (4). They suggested that insulin resistance is the common risk factor for a group of diseases, including hyperglycemia, hypertension hypertriglyceridemia, and low HDLcholesterol, and they named it $\mathrm{X}$ syndrome to emphasize its unknown aspects. About a year later, Kaplan added probably the most important component of this set: abdominal obesity (fatty deposits in subcutaneous tissues) (5). MetS is a multifactorial disease whose underlying disorder is insulin resistance (6). Obesity is responsible for the increased prevalence of MetS (7). The prevalence of obesity in the world following industrialization and mechanized living has reached a pandemic point during the recent century (8). Studies have shown that an increase in $\mathrm{BMI}$ is strongly associated with a higher risk of metabolic syndrome in obese and overweight people $(9,10)$. According to reports, $60 \%$ of individuals with MetS are obese (11). From 2003 to 2012, overall prevalence of the metabolic syndrome in the United States was 33\%, with significantly higher prevalence in women compared to men (12). There is a high prevalence of MetS in the Iranian adult population, with large variations based on different measurement criteria. The overall estimation of MetS prevalence was $36.9 \%$ based on the Adult Treatment Panel III (ATP III) criteria, 34.6\% according to the International Diabetes Federation (IDF), and 41.5\% (95\% CI: 29.8-53.2\%) based on the Joint Interim Societies (JIS) criteria. Also, the prevalence of MetS was lower in men than in women based on the ATP III criteria and the IDF criteria (13). MetS increases the risk of diabetes, cardiovascular diseases, gestational hypertension, preeclampsia, and preterm birth in pregnancy. The prevalence of MetS in pregnancy increases with decreasing glucose tolerance. Previous studies have also shown that glycemic profile is a useful diagnostic tool for identifying MetS-related metabolic abnormalities in pregnancy and predicting severe perinatal outcomes (APO) $(14,15)$.

On the other hand, newborns are exposed to a stressful intrauterine environment caused by metabolic syndrome and its components. Therefore, the risk of macrosomia, hypoglycemia, preterm labor, intrauterine growth retardation, and jaundice increases in these newborns (16). Although there are few studies on MetS during pregnancy and its effect on developing fetus and the newborns, the results of the studies focusing on individual components of MetS indicate the effect of the components of this syndrome on neonatal outcomes. The literature suggests an association between maternal lipid profile and neonatal anthropometric indices (17-19). For example, Mudd et al (2015) indicated that HDL and TG levels were related to birth weight among overweight/obese women, while birth weight was related to TC among normal weight women (20). In addition, it is shown that gestational diabetes or even impaired glucose tests were associated with birth weight and neonatal outcomes such as jaundice (21). The risk of jaundice in newborns of diabetic mothers is more than normal newborns. There are numerous reasons for incidence of hyperbilirubinemia in newborns of diabetic mothers, including prematurity, polycythemia, and macrosomia (22). Moreover, it is observed that newborns of obese or overweight mothers are mostly macrosomia and need prolonged hospital readmission $(23,24)$. On the other hand, newborns that are large for their gestational age (LGA) and macrosomia are exposed to a stressful intrauterine environment caused by components of metabolic syndrome. Therefore, they are at risk of developing MetS in their future life, and the cycle of obesity and insulin resistance continues in the next generation (25).

This study was performed to determine the relationships between MetS and its components in 24-28 weeks of gestation on neonatal outcomes (weight, height, head circumference, jaundice during the first 24 hours after birth, and rehospitalization of the newborn due to jaundice in the first 10 days after birth).

\section{Methods}

This prospective cohort study was performed on 238 pregnant women attending Nilou and Shahid Akbarabadi laboratories in Tehran in 2014. To prevent selection bias, convenience sampling was used and all pregnant women who met the inclusion criteria were enrolled in the study. The 2 selected laboratories, located in the north and south of Tehran, are among the largest laboratories in Tehran; thus, provide service to people with different socioeconomic status. The study population consisted of pregnant women who referred to the laboratories to have their routine glucose challenge test (GCT) with 50 gr glucose. The inclusion criteria were as follow: (1) gestational age: 2428 weeks; (2) mother's age: 18-45 years; (3) singleton pregnancy; (4) no chronic or systemic disease in mother; and (5) Iranian nationality.

All tests were analyzed in Shahid Akbarabadi laboratory.

The study was confirmed by the Ethics Committee of Faculty of Medical Sciences in Tarbiat Modares University, Tehran, Iran.

The present study was part of a larger study that investigated the association between metabolic syndrome and its components with maternal and neonatal outcomes. Given that no specific information was available on the prevalence of metabolic syndrome and its components in pregnancy and there was no similar study to use to estimate the sample size, the research team initially conducted a pilot study on 70 individuals. Then, the frequency and incidence of each of the components of metabolic syndrome and maternal and neonatal outcomes were evaluated. Finally, the sample size was estimated using the lowest incidence of outcome and the lowest incidence of the components of metabolic syndrome. The lowest incidence of components of metabolic syndrome was related to hypertension and the lowest incidence of neonatal outcomes was associated to neonatal hypothyroidism in neonatal screening tests. 
The sample size was calculated as follows:

$\mathrm{P}_{1}=$ Prevalence of hypertension in midpregnancy in mothers under study $P_{1}=0.071$

$\mathrm{P}_{2}=$ Prevalence of hypothyroidism in neonates born from mothers under study

$$
\begin{aligned}
& P_{2}=0.014, \mathrm{P}=\frac{P_{1}+P_{2}}{2}, \mathrm{P}=\frac{0.014+0.071}{2}=0.0425,1-\mathrm{P}=0.9575, \\
& \mathrm{Z}^{2}=7.84, \mathrm{~d}^{2}=0.0016, \mathrm{~N}=\frac{\mathrm{Z}^{2} \mathrm{P}(1-\mathrm{p})}{\mathrm{d}^{2}}, \\
& \mathrm{~N}=\frac{7.84 \times 0.0425 \times 0 / 9575}{\stackrel{0.0016}{\sim}}=199.39 \tilde{=} 200+\text { by calculating } \\
& \text { a } 10 \% \text { drop } 220
\end{aligned}
$$

Sample size was estimated using a sample size formula of 220. Considering that the cohort study was prospective and there was a chance of participants dropping out of the study in the follow-up period, the sample size increased to about $10 \%$, and a total of 241 patients were included. Fortunately, there were no drop-outs, but there were 3 cases of intrauterine fetal death (IUFD) who were excluded from the study.

The aims of the study were explained and written consent was obtained from the participants.

Upon entry into the study, a complete reproductive/medical history with some demographic characteristics were obtained by a trained midwife and recorded as reproductive and demographic data, including age, educational level, parity, ethnicity, height, prepregnancy weight, prepregnancy BMI, gestational age, use of complements during pregnancy (acid folic, iron, calcium and multivita$\mathrm{min}$ ), history of diabetes, hypertension, obesity, and dyslipidaemia. Gestational age in all participants was estimated by last menstrual period (LMP) and confirmed by early ultrasound estimations of gestational age. After history taking, mothers' weight, height, blood pressure, and later the result of glucose challenge test (GCT) were registered.

BMI was computed using self-reported prepregnancy weight and height measurement (weight in kilograms divided by the square of height in meters). The participants were asked about their prepregnancy weight. In case they did not remember it, the weight at first prenatal visit was considered as prepregnancy weight. The reason is that the first prenatal visit usually occurs in the first weeks of pregnancy (4-8 weeks) when there is very little difference between the present and prepregnancy weight. Systolic and diastolic blood pressures, which were measured upon entry into the study, were taken on the right arm after a 15-minute rest in a sitting position. The measurement was repeated after 10 minutes on the same arm and the mean value obtained from the 2 measures was registered as the participant's blood pressure. GCT results (blood sugar 1 hour after consumption of $50 \mathrm{gr}$ oral glucose in nonfasting condition and regardless of the last meal ) were obtained and registered at the laboratory, and values $\geq 140 \mathrm{mg} / \mathrm{dL}$ were considered as impaired results.

Then, the participants were asked to refer to the laboratory in fasting condition during the next week to give $5 \mathrm{cc}$ blood to have their high-density lipoprotein (HDL) and triglyceride (26) serum levels measured. Due to daily changes in blood triglyceride (26), TG, and HDL sampling are taken between 7-9 AM after 12-14 hours of fasting during the previous night. The triglyceride and HDL levels were measured by photometric method using the diagnosis kit manufactured by Pars Azmoon Company, Iran. Moreover, blood glucose level test in GCT test was conducted by enzymatic glucose oxidase method using Pars Azmoon Company kits. There is no definition for MetS in pregnancy and there are no data on diagnostic criteria for this syndrome during pregnancy in midwifery and gynecological references $(14,27-30)$. Thus, the criteria provided by the recent National Cholesterol Education Program, Adult Treatment Panel III (31) was adapted for the study population. Considering that the participants were pregnant, abdominal circumference was not used, and obesity was defined as a prepregnancy BMI higher than $30 \mathrm{~kg} / \mathrm{m}^{2}$. Moreover, given remarkable changes in the lipids level during pregnancy, hypertriglyceridemia was considered above the $75^{\text {th }}$ percentile. Also, HDL was considered below the $25^{\text {th }}$ percentile. Therefore, metabolic syndrome was diagnosed if 3 or more of the following risk factors were present: triglyceride level $\geq 249 \mathrm{mg} / \mathrm{dL}$; HDL-cholesterol level $<61 \mathrm{mg} / \mathrm{dL} ; \mathrm{GCT} \geq 130 \mathrm{mg} / \mathrm{dL}$, prepregnancy BMI $\geq 30 \mathrm{~kg} / \mathrm{m}^{2}$; and blood pressure level $\geq$ $130 / 85 \mathrm{mmHg}$. All participants went through routine prenatal care till delivery by an obstetrician in a private clinic, or in Akbarabadi hospital, or in a health center by a midwife. The neonatal anthropometric indices of birth weight, height, and head circumference were obtained and registered from the newborns' birth certificates. Jaundice in the first 24 hours after birth refers to cases that were examined and diagnosed by a neonatologist. One of the outcomes studied was hospitalization of neonates due to jaundice in the first 10 days of birth, which was defined as follows in the present study: if a neonate was hospitalized due to jaundice above $12 \mathrm{mg}$ and received phototherapy after the mother was discharged.

Statistical analysis was performed through descriptive statistics, including mean, standard deviation, frequency, and percentage, Mann-Whitney test, Chi-square test, Fisher's exact test, linear and logistic regression in SPSS 21.0. $P$ value less than 0.05 was considered significant.

\section{Results}

Overall, 241 pregnant women with gestational age of 24-28 weeks were enrolled in the study. Three participants were excluded due to intrauterine fetal death (IUFD) occurrence; thus, 238 pregnant women were studied.

The mean age of the pregnant women was $29.59 \pm 4.55$ years. Most of the participants $(156 ; 73.2 \%)$ aged 25-35 years had university education and normal prepregnancy BMI. Moreover, most of them were primiparous, with the mean birth age of $38.29 \pm 1.7$ weeks; also, the mean weight of the newborns was $3147 \pm 4.43$ gr (Table 1 ).

The associations between metabolic syndrome in pregnancy and its components with neonatal anthropometric are presented in Table 2.

There was a significant association between blood hypertriglyceridemia in weeks 24-28 and anthropometric 


\begin{tabular}{lc}
\hline Table 1. Demographic information of mothers $(\mathrm{N}=238)$ & \\
\hline Demographic characteristics & Number (\%) \\
\hline Age & \\
$25 \leq$ & $42(17.8)$ \\
$25-35$ & $175(73.2)$ \\
$35 \geq$ & $21(9)$ \\
Education & $15(6.6)$ \\
Primary & $73(30.5)$ \\
Diploma & $150(62.9)$ \\
University & $136(57.3)$ \\
Pregnancy number & $102(42.7)$ \\
Primiparous & \\
Multiparous & $162(68.1)$ \\
Prepregnancy BMI (kg/m $\left.{ }^{2}\right)$ & $76(31.9)$ \\
$30<$ & $19(8)$ \\
$30 \geq$ & $210(88.2)$ \\
Pregnancy age during delivery (week) & $9(3.8)$ \\
$37<$ & \\
$37-40$ & $127(53.5)$ \\
$40>$ & $111(46.5)$ \\
Neonatal characteristics & $10(4.2)$ \\
Boy & $44(18.5)$ \\
Girl & \\
Jaundice on the first day of birth & $13(5.6)$ \\
Re-hospitalization due to jaundice in the first 10 days after birth & $223(93.4)$ \\
Birth weight (gr) & $2(1)$ \\
$2500 \leq$ & $3148(4.46)$ \\
$2500-4000$ & $49.68(2.48)$ \\
$4000 \geq$ & $34.24(1.70)$ \\
Birth weight (gr) & \\
Birth height (cm) & \\
Birth head circumference (cm) & \\
Data are means - standard deviation (SD) or $\mathrm{n}(\%)$. & \\
\hline &
\end{tabular}

Data are means - standard deviation (SD) or $\mathrm{n}(\%)$.

\begin{tabular}{|c|c|c|c|c|c|c|}
\hline \multirow{2}{*}{$\begin{array}{l}\text { Metabolic Syndrome } \\
\text { Components }\end{array}$} & \multirow[t]{2}{*}{ Level } & \multicolumn{5}{|c|}{ Neonatal outcomes } \\
\hline & & $\begin{array}{l}\text { Weight } \\
\text { (gr) }\end{array}$ & $\begin{array}{l}\text { Height } \\
(\mathrm{cm})\end{array}$ & $\begin{array}{l}\text { Head circumference } \\
(\mathrm{cm})\end{array}$ & $\begin{array}{c}\text { Jaundice of the first } 24 \\
\text { hours after birth }\end{array}$ & $\begin{array}{l}\text { Re-hospitalization due to } \\
\text { jaundice }\end{array}$ \\
\hline \multirow[t]{3}{*}{$\mathrm{Bp}(\mathrm{mm} / \mathrm{gh})$} & $\geq 130.85$ & 3198 & 49.81 & 34.40 & $1(10)$ & $2(4.5)$ \\
\hline & $<130.85$ & 3145 & 49.68 & 34.22 & $9(90)$ & $42(95.5)$ \\
\hline & p-value & $0.654 *$ & $0.741^{*}$ & $1 *$ & 0.673 r & $0.527 \mathrm{r}$ \\
\hline \multirow[t]{3}{*}{ BMI $\left(\mathrm{kg} / \mathrm{m}^{2}\right)$} & $\geq 30$ & 3151 & 49.71 & 34.50 & $1(10)$ & $4(9.1)$ \\
\hline & $<30$ & 3105 & 49.30 & 34.23 & $9(90)$ & $40(90.9)$ \\
\hline & p-value & $0.521 *$ & $0.243^{*}$ & $0.604 *$ & 0.528 × & $0.399 \times$ \\
\hline \multirow[t]{3}{*}{ GCT (mg/dl) } & $\geq 140$ & 3163 & 49.71 & 34.18 & $7(70)$ & $18(40.9)$ \\
\hline & $<140$ & 3139 & 49.67 & 34.29 & $3(30)$ & $26(59.1)$ \\
\hline & p-value & $0.971 *$ & $0.817^{*}$ & $0.375^{*}$ & $0.041 \mathrm{x}$ & 0.885 х \\
\hline \multirow[t]{3}{*}{ TG (mg/dl) } & $\geq 249$ & 3206 & 50 & 34.16 & $7(10)$ & $15(34.1)$ \\
\hline & $<249$ & 2982 & 48.69 & 33.79 & $3(10)$ & $29(65.9)$ \\
\hline & $\mathrm{p}$-value & $0.001 *$ & $0.006^{*}$ & $0.765^{*}$ & 0.003 х & 0.083 r \\
\hline \multirow[t]{3}{*}{ HDL (mg/dl) } & $\geq 61$ & 3175 & 49.92 & 34.69 & $8(80)$ & $13(29.5)$ \\
\hline & $<61$ & 3147 & 49.67 & 34.22 & 2 & $31(70.5)$ \\
\hline & $\mathrm{p}$-value & $0.454^{*}$ & $0.213^{*}$ & $0.457^{*}$ & 0.033 r & 0.286 r \\
\hline \multirow[t]{3}{*}{ Metabolic syndrome } & Yes & 3292 & 50.26 & 34.50 & $3(30)$ & $38(88.6)$ \\
\hline & No & 3139 & 49.65 & 34.23 & $7(70)$ & $5(11.4)$ \\
\hline & p-value & $0.228^{*}$ & $0.189 *$ & $0.526^{*}$ & $0.002 \times$ & 0.125 r \\
\hline
\end{tabular}

\footnotetext{
BP, blood pressure; BM

*Mann-Whitney U Test

$v$ Chi-squared test or Fisher exact test whenever $\mathrm{n}<5$ compared with controls

$\mathrm{P}<.05$ was defined as significant.
}

indices, including weight, height, and jaundice in the first 24 hours of birth. On the one hand, low HDL and impaired GCT were significantly correlated with jaundice in the first 24 hours after birth $(\mathrm{P}<0.05)$. MetS in midpregnancy had a significant association with jaundice in the first 24 hours after birth $(\mathrm{P}=0.002)$.

Linear regression test was used to control underlying variables, including age, education, number of pregnancies, age at delivery, newborn gender, and history of low birth weight. The results showed a direct association be- tween increased blood triglyceride of the mother and newborn's weight $(\mathrm{B}=0.11, \mathrm{P}=0.011)$ and height $(\mathrm{B}=0.14$, $\mathrm{P}=0.007)$. Moreover, among other components of metabolic syndrome, increased BMI had a significant direct association with the newborn's weight $(\mathrm{B}=0.11, \mathrm{P}=0.023)$ and height $(\mathrm{B}=0.12, \mathrm{P}=0.023)$. Also, decreased HDL had a significant inverse association with birth weight $(B=0.09$, $\mathrm{P}=0.042$ ). MetS in midpregnancy had a significant association with weight $(\mathrm{B}=0.18, \mathrm{P}=0.003)$ and height $(\mathrm{B}=0.18$, $\mathrm{P}=0.009$ ) in the newborn (Table 3 ).

\footnotetext{
$4 \quad$ http://mjiri.iums.ac.ir 
Table 3. The effect of MetS and its components on neonatal anthropometric indices in the presence of the underlying variables - linear regression test

\begin{tabular}{|c|c|c|c|c|c|c|}
\hline \multirow{3}{*}{$\begin{array}{l}\text { Effective } \\
\text { variables }\end{array}$} & \multicolumn{5}{|c|}{ Neonatal anthropometric indices } & \\
\hline & \multicolumn{2}{|c|}{$\begin{array}{l}\text { Weight at birth } \\
\text { (gr) }\end{array}$} & \multicolumn{2}{|c|}{ Height at birth $(\mathrm{cm})$} & \multicolumn{2}{|c|}{ Head circumference $(\mathrm{cm})$} \\
\hline & P-value & $\begin{array}{c}\text { Standardized } \\
\text { Coefficients (Beta) }\end{array}$ & P-value & $\begin{array}{l}\text { Standardized Coeffi- } \\
\text { cients (Beta) }\end{array}$ & P-value & $\begin{array}{c}\text { Standardized } \\
\text { Coefficients (Beta) }\end{array}$ \\
\hline Mother age (year & 0.511 & -0.03 & 0.025 & -0.13 & 0.478 & -0.04 \\
\hline Education (year) & 0.007 & 0.15 & $<0.001$ & 0.26 & $<0.001$ & 0.28 \\
\hline N. of pregnancy & 0.085 & 0.09 & 0.022 & 0.13 & 0.006 & 0.19 \\
\hline $\begin{array}{l}\text { History of low- } \\
\text { birth weight }\end{array}$ & 0.002 & -0.15 & 0.026 & -0.12 & 0.105 & -0.09 \\
\hline $\begin{array}{l}\text { gestational age at } \\
\text { delivery (week) }\end{array}$ & $<0.001$ & 0.66 & $<0.001$ & 0.54 & $<0.001$ & 0.45 \\
\hline Newborn's Gender & 0.001 & -0.15 & 0.055 & -0.09 & $<0.001$ & -0.18 \\
\hline BMI & 0.023 & 0.11 & 0.023 & 0.12 & 0.977 & 0.002 \\
\hline Blood pressure & 0.454 & -0.04 & 0.411 & -0.04 & 0.801 & 0.01 \\
\hline GCT & 0.321 & 0.05 & 0.503 & 0.03 & 0.397 & -0.05 \\
\hline Triglyceride & 0.011 & 0.11 & 0.007 & 0.14 & 0.411 & 0.04 \\
\hline Cholesterol - HDL & 0.042 & 0.09 & 0.311 & 0.05 & 0.597 & 0.03 \\
\hline MetS (yes) & 0.003 & 0.18 & 0.009 & 0.18 & 0.376 & 0.06 \\
\hline
\end{tabular}

BP, blood pressure; BMI, Body Mass Index; GCT, Glucose Challenge Test; HDL-C, high-density lipoprotein cholesterol; TG, triglycerides.

$\mathrm{P}<.05$ was defined as significant.

Table 4. Examining effective factors in development of jaundice in the first 24 hours of birth and rehospitalization due to jaundice - logistic regression test

\begin{tabular}{|c|c|c|c|c|c|c|c|c|}
\hline \multirow{4}{*}{ Model } & \multirow[t]{2}{*}{ Effective factors } & \multirow[t]{2}{*}{ p-vale } & \multirow{2}{*}{$\begin{array}{c}\text { Non- } \\
\text { adjusted } \\
\text { Odds ratio (OR) }\end{array}$} & \multicolumn{2}{|c|}{$\begin{array}{c}\text { Confidence of } \\
95 \%\end{array}$} & \multirow{2}{*}{$\begin{array}{c}\text { Adjusted } \\
\text { odds ratio } \\
(\mathrm{AOR})\end{array}$} & \multicolumn{2}{|c|}{ Confidence of $95 \%$} \\
\hline & & & & Lower & Upper & & Lower & Upper \\
\hline & Gestational age at birth & 0.922 & 0.83 & 0.65 & 1.05 & 0.97 & 0.60 & 1.57 \\
\hline & Newborn gender & 0.955 & 1.13 & 0.31 & 4.01 & 1.04 & 0.25 & 4.25 \\
\hline \multirow{6}{*}{$\begin{array}{l}\text { Effective factors in } \\
\text { jaundice in the first } 24 \\
\text { hours of birth }\end{array}$} & Newborn weight & 0.726 & 0.99 & 0.99 & 1.000 & 1.0 & 0.99 & 1.001 \\
\hline & Blood pressure $\geq 130.85$ & 0.123 & 1.57 & 0.187 & 13.2 & 0.04 & 0.001 & 2.46 \\
\hline & $\mathrm{BMI} \geq 30$ & 0.586 & 1.69 & 0.20 & 14.3 & 0.39 & 0.01 & 10.9 \\
\hline & $\mathrm{GCT} \geq 140$ & 0.547 & 1.13 & 0.21 & 9.62 & 1.66 & 0.31 & 8.82 \\
\hline & Triglyceride $\geq 249$ & 0.011 & 7.89 & 1.97 & 31.6 & 8.89 & 1.65 & 47.7 \\
\hline & cholesterol $-\mathrm{HDL}<61$ & 0.987 & 0.72 & 0.19 & 2.263 & 0.98 & 0.15 & 6.25 \\
\hline \multirow{10}{*}{$\begin{array}{l}\text { Factors effective in } \\
\text { readmission due to } \\
\text { jaundice }\end{array}$} & Metabolic syndrome & 0.012 & 7.71 & 1.77 & 33.6 & 56.23 & 2.19 & 1439.2 \\
\hline & gestational at birth & 0.026 & 0.84 & 0.71 & 0.99 & 0.73 & 0.57 & 0.95 \\
\hline & Newborn gender & 0.517 & 0.73 & 0.37 & 1.43 & 0.79 & 0.39 & 1.60 \\
\hline & Newborn weight & 0.096 & 1.0 & 0.99 & 1.001 & 1.0 & 1.0 & 1.02 \\
\hline & Blood pressure $\geq 130.85$ & 0.114 & 0.61 & 0.13 & 2.79 & 0.17 & 0.02 & 1.02 \\
\hline & $\mathrm{BMI} \geq 30$ & 0.625 & 1.66 & 0.50 & 5.49 & 1.44 & 0.32 & 6.36 \\
\hline & $\mathrm{GCT} \geq 140$ & 0.314 & 0.75 & 0.33 & 1.26 & 0.65 & 0.29 & 1.47 \\
\hline & Triglyceride $\geq 249$ & 0.124 & 1.76 & 0.86 & 3.58 & 1.83 & 0.84 & 3.94 \\
\hline & cholesterol $-\mathrm{HDL}<61$ & 0.536 & 1.37 & 0.66 & 2.84 & 1.27 & 0.58 & 2.77 \\
\hline & Metabolic syndrome & 0.127 & 2.35 & 0.76 & 7.28 & 4.11 & 0.66 & 25.4 \\
\hline
\end{tabular}

OR, odds ratio; CI, confidence interval; BP, blood pressure; BMI, Body Mass Index; GCT, Glucose Challenge Test; HDL-C, high-density lipoprotein cholesterol; TG, triglycerides.

$\mathrm{P}<.05$ was defined as significant.

In the present study, using logistic regression test and controlling for the effective underlying variables, including gestational age at birth, the newborn's gender, and birth weight, it was determined whether MetS can cause jaundice during the first 24 hours of birth or cause readmission within 10 days after birth.

The results showed that triglyceride $\geq 249$ (OR=8.89, $95 \% \mathrm{CI}=1.65-47.7, \mathrm{P}=0.011)$ and MetS in midpregnancy $(\mathrm{OR}=56.23,95 \% \mathrm{CI}=2.19-1439.2, \mathrm{P}=0.012)$ were significant predictors of jaundice (Table 4 ).

\section{Discussion}

The aim of the present study was to determine the associations between metabolic syndrome and its components in midpregnancy on neonatal outcomes. The present study found that MetS in midpregnancy had a significant relationship with weight, height, and jaundice in the first 24 hours of birth. Among the MetS components, there was a direct relationship between blood triglyceride level in midpregnancy and prepregnancy BMI with neonatal anthropometric indices, including weight and height. Moreover, birth weight increased with a rise in cholesterol HDL. Triglyceride $\geq 249$, low cholesterol - HDL, and impaired GCT were significant predictors of jaundice during the first 24 hours after birth.

Maternal serum TG levels were positively correlated with neonatal birth weight and height in this study, which is consistent with previous studies in Iran (32) and similar to Asian women (33-35). Whyte (2013) indicated that increased fasting maternal triglyceride was associated with increased offspring birth weight, independent of maternal age, BMI, and GDM status. (36). Son's study in Korea focused on measuring serum lipids in weeks 24-32 among diabetic women, and the results showed that maternal triglyceride levels were higher among mothers with LGA newborns compared to other mothers. It was rec- 
ommended that measuring maternal triglyceride level in midpregnancy can help identify women who are more likely to have LGA births. Blood levels of HDL and total cholesterol had no relationship with birth weight (35). Moreover, another study reported that an increase of 1 unit in triglyceride in early pregnancy even in nondiabetic women increased the risk of LGA newborn. In that study, there was no relationship between total cholesterol and neonatal outcomes (37).

The results of this study were consistent with those of Mossayebi's study (2014) (32) that indicated maternal triglyceride levels may be a significant predictor of fetal size in midpregnancy but not in early pregnancy. The findings of all the above-mentioned studies are in line with those of the present study, and it can be concluded that maternal triglyceride level is an independent predictor of neonatal birth weight, the presence of macrosomia, and large-for-gestational age (LGA). A positive relationship between maternal triglyceride levels and birth weight is confusing, as maternal triglyceride cannot cross out the placenta (38). According to a physiological mechanism, it is hypothesized that maternal triglycerides are degraded by the placental lipoprotein lipase to free fatty acids, which in turn increases the free fatty acids and their passage through the placenta (38).

Resistance to insulin in late pregnancy clarifies the relationship between maternal triglyceride and fetal development. In fact, hypertriglyceridemia is one of the features of resistance to insulin among nonpregnant adults (39).

Moreover, here, it was found that maternal serum HDL levels in midpregnancy were also positively related to infant birth weight. The results of several studies showed a positive relationship between mothers' HDL levels and fetal development and also the risk of macrosomia (40, 41 ), which is in agreement with the results of the present study. For example, Mirsa (2011) indicated that blood HDL levels in pregnancy among obese or overweight women had a significant inverse association with birth weight (19). Ye K (2015) reported that maternal HDL and TG levels were related to neonatal body size (42). Also, Mudd (2015) stated that maternal HDL and TG levels were related to birth weight among overweight/obese women (20).

However, Mitra found that HDL cholesterol was negatively correlated with birth weight, height, and chest circumference, whereas triglycerides and LDL cholesterol were positively correlated with other anthropometric indices, but not with birth weight. Increased fetal weight gain related to dyslipidemia is either due to increased nutrient transfer across the placenta or is associated with hyperinsulinemia, which is the indicator of insulin resistance (43).

The results of a study in China by Wen-Yuan Jin showed that an increase in triglyceride and a decrease in HDL are associated with increased risk of neonatal macrosomia and gestational diabetes (44).

Results of this study are somewhat in agreement with the above studies because we found that triglycerides had a positive relationship with birth weight and length, while HDL had a significant negative correlation with weight, but not with birth height.
However, in Son et al study, in 2010 in Korea, no significant correlation was found between total cholesterol, maternal fasting glucose, or HDL cholesterol levels with newborn birth weight. This difference with findings of the present study may be due to the differences in participants' condition, which was only GDM cases in Son study (35). Emet (2013) did not discover any relationship between birth weight and changes in HDL, LDL, and total cholesterol levels in pregnancy (33).

The mechanisms through which maternal HDL may influence birth weight is not completely discovered. However, HDL has several possible roles that can influence fetal growth and development (45), as it has an important role in cholesterol transport and homeostasis (46). In addition, HDL has anti-inflammatory, antioxidant, and antithrombotic properties (45) which may influence placental circulation and fetal growth. The literature suggests an association between birth weight and birth of LGA newborn with prepregnancy BMI $(23,24)$. In their study, Esma'ili and Gashtasbi pointed out that prepregnancy BMI played an important role in predicting birth weight, and birth weight was significantly lower among normal weight women compared to overweight/obese women $(47,48)$. Zhao also showed that maternal overweight and obesity are correlated with an increased risk of macrosomia and large-for-gestational age (49).

In most studies, prepregnancy BMI is referred to as an effective factor in fetal growth during pregnancy and neonatal anthropometric indices, the best correlation being found with birth weight. This may be related to insulin resistance, which is often present in obese or overweight women during pregnancy. Insulin resistance causes metabolic disorders, resulting in an increase in nutrients to the fetus, which receives large amounts of glucose through the placenta, resulting in hyperinsulinemia and accelerated fetal growth. Pregnant women with insulin resistance have a higher concentration of triglycerides, which are broken down by placental lipases into smaller molecules and transported to the fetal circulation, bringing more energy to the fetus $(50,51)$. In addition, insulin resistance enhances leucine metabolism and increases macrosomia and LGA by increasing the rate of amino acids crossing the fetus and hyperinsulinemia (52).

In the present study, it was observed that MetS and hypertriglyceridemia had a significant relationship with jaundice during the first 24 hours of birth, and presence of MetS and hypertriglyceridemia in pregnancy increased the probability of development of jaundice about 56 and 9 times, respectively. Triglyceride can lead to an increase in the newborn's weight, increasing the risk of polycythemia and increased blood bilirubin (53). Also, diabetes during pregnancy has considerable adverse effects on the mother and her fetus or the neonate. Mother's hyperglycemia may induce hyperinsulinemia and pancreatic Beta cells hyperplasia in fetus. Excess insulin secretion in fetus blood may cause macrosomia, increase basal metabolism rate, and increase oxygen consumption and even fetus hypoxemia. Fetal hypoxia may be followed by erythropoietin overproduction, red blood cell hyperplasia, and increased hematocrit level. Polycythemia may enhance blood circulation 
and cause hyperbilirubinemia $(54,55)$.

A meta-analysis in 2015 showed that triglycerides significantly increased in women with GDM compared to women without insulin resistance, and this finding persisted every 3 trimesters of pregnancy. HDL-C levels were significantly lower in women with GDM compared to those without GDM in the second and third trimesters of pregnancy (56).

Based on the above findings, there was a close relationship between the components of the metabolic syndrome and its effect on the neonatal anthropometric indices and outcomes.

Some limitations should be noted: The first limitation of this study stemmed from the lack of evidence-based identified definition for MetS in pregnancy; thus, a pregnancy self-modified version of ATP III definition was used in this study. Second, the generalizability of the results was not possible due to the small sample size of the study and the sampling method (convenience sampling method).

However, the strength of this study was that sampling was done in 2 of the largest laboratories of Tehran, one of which was located in the suburbs and the other downtown to where a large number of people referred from all over the city; and this may resolve the generalizability problem of the results to some extent. Moreover, metabolic syndrome components such as blood pressure, maternal lipids, and GCT in midpregnancy were precisely measured by the researcher and were not self-reported. Furthermore, the study topic can pave the way for further studies in the future. Thus, it is recommended that similar studies be conducted in larger scopes and in different regions of the country. Moreover, conducting prospective studies are also suggested to determine the relationship between MetS and its components with maternal and neonatal outcomes.

\section{Conclusion}

Increased levels of triglyceride and cholesterol HDL have a correlation with the newborn's weight and height. Metabolic syndrome and its components, including hypertriglyceridemia, low cholesterol HDL, and impaired GCT, are significant predictors of jaundice during the first 24 hours after birth. Therefore, attention should be paid to metabolic syndrome and its components to improve pregnancy and neonatal outcomes.

\section{Acknowledgements}

This study was performed as a thesis project for receiving M.Sc. degree in midwifery in the Faculty of Medical Sciences, Tarbiat Modares University, Tehran, Iran (ethics code: 52/5002; registration code: 2015-2-10).

\section{Conflict of Interests}

The authors declare that they have no competing interests.

\section{References}

1. Azevedo A, Santos AC, Ribeiro L, Azevedo I. The metabolic syndrome. Oxidative stress, inflammation and angiogenesis in the metabolic syndrome: Springer; 2009. p. 1-19.

2. Catov JM, Dodge R, Yamal JM, Roberts JM, Piller LB, Ness RB.
Prior preterm or small-for-gestational-age birth related to maternal metabolic syndrome. Obstet Gynecol. 2011;117(2 Pt 1):225.

3. Gami AS, Witt BJ, Howard DE, Erwin PJ, Gami LA, Somers VK, et al. Metabolic syndrome and risk of incident cardiovascular events and death: a systematic review and meta-analysis of longitudinal studies. J Am Coll Cardiol. 2007;49(4):403-14.

4. Reaven GM. Role of insulin resistance in human disease. Diabetes. 1988;37(12):1595-607.

5. Kaplan NM. The deadly quartet: upper-body obesity, glucose intolerance, hypertriglyceridemia, and hypertension. Arch Intern Med. 1989;149(7):1514-20.

6. Polsky S, Ellis SL. Obesity, insulin resistance, and type 1 diabetes mellitus. Curr Opin Endocrinol Diabetes Obes. 2015;22(4):277-82.

7. Nikolopoulou A, Kadoglou NP. Obesity and metabolic syndrome as related to cardiovascular disease. Expert Rev Cardiovasc Ther. 2012;10(7):933-9.

8. Moradi F, Shariat F, Mirzaeian K. Identifying the effects of training of obesity prevention and weight management an the knowledge of clients to neighborhood health house in the city of Tehran. Iran J Health Educ Health Promot. 2013;1(1):33-40.

9. Hasani-Ranjbar S, Amoli MM, Tabatabaei-Malazy O, Rumi Y, Tavakkoly-Bazzaz J, Samimi H, et al. Effect of adiponectin gene polymorphisms on waist circumference in patients with diabetes. J Diabetes Metab Disord. 2012;11(1):14.

10. Payab M, Amoli MM, Qorbani M, Hasani-Ranjbar S. Adiponectin gene variants and abdominal obesity in an Iranian population. Eat Weight Disord. 2017;22(1):85-90.

11. Nesto RW. Obesity: a major component of the metabolic syndrome. Tex Heart Inst J. 2005;32(3):387.

12. Aguilar M, Bhuket T, Torres S, Liu B, Wong RJ. Prevalence of the metabolic syndrome in the United States, 2003-2012. JAMA. 2015;313(19):1973-4.

13. Amirkalali B, Fakhrzadeh H, Sharifi F, Kelishadi R, Zamani F, Asayesh H, et al. Prevalence of Metabolic Syndrome and Its Components in the Iranian Adult Population: A Systematic Review and Meta-Analysis. Iran Red Cresc Med J. 2015;17(12).

14. Chatzi L, Plana E, Daraki V, Karakosta P, Alegkakis D, Tsatsanis C, et al. Metabolic syndrome in early pregnancy and risk of preterm birth. Am J Epidemiol. 2009;170(7):829-36.

15. Negrato CA, Jovanovic L, Rafacho A, Tambascia MA, Geloneze B, Dias A, et al. Association between different levels of dysglycemia and metabolic syndrome in pregnancy. Diabetol Metabol Syndrome. 2009;1(1):3.

16. sourinejad $\mathrm{H}$, moghadam banaem 1 , niyati $\mathrm{s}$. The metabolic syndrome and its components in midpregnancy in Tehran, 2013-14. J Urmia Nurs Midwif Fac. 2016;14(5):465-73.

17. Boghossian NS, Mendola P, Liu A, Robledo C, Yeung EH. Maternal serum markers of lipid metabolism in relation to neonatal anthropometry. J Perinatol. 2017;37(6):629.

18. Schaefer-Graf UM, Graf K, Kulbacka I, Kjos SL, Dudenhausen J, Vetter $\mathrm{K}$, et al. Maternal lipids as strong determinants of fetal environment and growth in pregnancies with gestational diabetes mellitus. Diabetes care. 2008.

19. Misra VK, Trudeau S, Perni U. Maternal serum lipids during pregnancy and infant birth weight: the influence of prepregnancy BMI. Obesity. 2011;19(7):1476-81.

20. Mudd LM, Holzman CB, Evans RW. Maternal mid-pregnancy lipids and birthweight. Acta Obstet Gynecol Scand. 2015;94(8):852-60.

21. Ghosh S, Ghosh K. Maternal and neonatal outcomes in gestational diabetes mellitus. J Indian Med Assoc. 2013;111(5):330-1, 6.

22. Gleason C. Devaskar SU Avery's diseases of the newborn. 9 th ed. Elsevier Saunders; 2012.

23. Athukorala C, Rumbold AR, Willson KJ, Crowther CA. The risk of adverse pregnancy outcomes in women who are overweight or obese. BMC pregnancy Childbirth. 2010;10(1):56

24. Retnakaran R, Ye C, Hanley AJ, Connelly PW, Sermer M, Zinman $\mathrm{B}$, et al. Effect of maternal weight, adipokines, glucose intolerance and lipids on infant birth weight among women without gestational diabetes mellitus. CMAJ. 2012;184(12):1353-60.

25. Boney CM, Verma A, Tucker R, Vohr BR. Metabolic syndrome in childhood: association with birth weight, maternal obesity, and gestational diabetes mellitus. Pediatrics. 2005;115(3):e290-e6.

26. Rastgo nahid Gm, sade farid B. Effectiveness increased sexual knowledge on marital satisfaction of married women. Clin Psychol Stud. 2014;5(17):35-48. 
27. Baliutavičienė D, Buinauskienè JB, Petrenko V, Danytė E, Žalinkevičius R. Gestational diabetes, obesity, and metabolic syndrome diagnosed during pregnancy. Metab Syndr Relat Disord. 2012;10(3):214-7.

28. Bartha JL, González-Bugatto F, Fernández-Macías R, GonzálezGonzález NL, Comino-Delgado R, Hervías-Vivancos B. Metabolic syndrome in normal and complicated pregnancies. Eur J Obstet Gynecol Reprod Biol. 2008;137(2):178-84.

29. Bo S, Menato G, Gallo ML, Bardelli C, Lezo A, Signorile A, et al. Mild gestational hyperglycemia, the metabolic syndrome and adverse neonatal outcomes. Acta Obstet Gynecol Scand. 2004;83(4):335-40.

30. Horváth B, Kovács L, Riba M, Farkas G, Bödecs T, Bódis J. The metabolic syndrome and the risks of unfavourable outcome of pregnancy. Orvosi hetilap. 2009;150(29):1361-5.

31. Grundy SM, Cleeman JI, Daniels SR, Donato KA, Eckel RH, Franklin BA, et al. Diagnosis and management of the metabolic syndrome. Circulation. 2005;112(17):2735-52.

32. Mossayebi E, Arab Z, Rahmaniyan M, Almassinokiani F, Kabir A. Prediction of neonates' macrosomia with maternal lipid profile of healthy mothers. Pediatr Neonatol. 2014;55(1):28-34.

33. Emet T, Üstüner I, Güven SG, Balık G, Ural ÜM, Tekin YB, et al. Plasma lipids and lipoproteins during pregnancy and related pregnancy outcomes. Arch Gynecol Obstet. 2013;288(1):49-55.

34. Hwang J, Choi H, Kim H, Jang W, Ha E, Park C, et al. Relationship of maternal grain intake and serum triglyceride levels with infant birth weight: Mothers and Children's Environmental Health (MOCEH) study. Eur J Clin Nutr. 2015;69(6):676.

35. Son GH, Kwon JY, Kim YH, Park YW. Maternal serum triglycerides as predictive factors for large-for-gestational age newborns in women with gestational diabetes mellitus. Acta Obstet Gynecol Scand. 2010;89(5):700-4.

36. Whyte K, Kelly H, O’Dwyer V, Gibbs M, O’Higgins A, Turner MJ. Offspring birth weight and maternal fasting lipids in women screened for gestational diabetes mellitus (GDM). Eur J Obstet Gynecol Reprod Biol. 2013;170(1):67-70.

37. Vrijkotte TG, Krukziener N, Hutten BA, Vollebregt KC, van Eijsden M, Twickler MB. Maternal lipid profile during early pregnancy and pregnancy complications and outcomes: the ABCD study. J Clin Endocrinol Metab. 2012;97(11):3917-25.

38. Knopp RH, Bonet B, Zhu X. Lipid metabolism in pregnancy. Principles of Perinatal-Neonatal Metabolism: Springer; 1998. p. 221-58.

39. Mantzoros C, Flier J. Insulin resistance: the clinical spectrum. Adv Endocrinol Metab. 1995;6:193.

40. Clausen T, Burski T, Øyen N, Godang K, Bollerslev J, Henriksen T. Maternal anthropometric and metabolic factors in the first half of pregnancy and risk of neonatal macrosomia in term pregnancies. A prospective study. Eur J Endocrinol. 2005;153(6):887-94.

41. Di Cianni G, Miccoli R, Volpe L, Lencioni C, Ghio A, Giovannitti $\mathrm{M}$, et al. Maternal triglyceride levels and newborn weight in pregnant women with normal glucose tolerance. Diabet Med. 2005;22(1):21-5.

42. Ye K, Bo QL, Du QJ, Zhang D, Shen Y, Han YP, et al. Maternal serum lipid levels during late pregnancy and neonatal body size. Asia Pac J Clin Nutr. 2015;24(1):138-43.

43. Mitra S, Misra S, Nayak PK, Sahoo JP. Effect of maternal anthropometry and metabolic parameters on fetal growth. Indian J Endocrinol Metab. 2012;16(5):754.

44. Jin WY, Lin SL, Hou RL, Chen XY, Han T, Jin Y, et al. Associations between maternal lipid profile and pregnancy complications and perinatal outcomes: a population-based study from China. BMC Pregnancy Childbirth. 2016;16(1):60.

45. Ansell BJ, Watson KE, Fogelman AM, Navab M, Fonarow GC. High-Density Lipoprotein FunctionRecent Advances. J Am Coll Cardiol. 2005;46(10):1792-8.

46. McConihay JA, Honkomp AM, Granholm NA, Woollett LA. Maternal high density lipoproteins affect fetal mass and extraembryonic fetal tissue sterol metabolism in the mouse. J Lipid Res. 2000;41(3):424-32.

47. Goshtasebi A BL, Âlizadeh Rodbary M, Bakouei S. The Association Between Preconception Body Mass Index and Pregnancy Weight gain on Birth Weight. J Mazandaran Uni Med Sci. 2011;21(84):81-5.

48. Esmaili H FA, Najmabadi KM, Dadgar S, Karimi A, Gelayami MK. The Relationship between maternal body mass index at the beginning of pregnancy and infants' birth weight and pregnancy outcomes. Iran J Obstet Gynecol Inferti. 2014;16(85):1-10.
49. Zhao R, Xu L, Wu M, Huang S, Cao X. Maternal prepregnancy body mass index, gestational weight gain influence birth weight. Women Birth. 2018;31(1):e20-e5.

50. Gauster M, Hiden U, Blaschitz A, Frank S, Lang U, Alvino G, et al. Dysregulation of placental endothelial lipase and lipoprotein lipase in intrauterine growth-restricted pregnancies. J Clin Endocrinol Metab. 2008;92(6):2256-63.

51. Gil-Sánchez A, Demmelmair H, Parrilla JJ, Koletzko B, Larqué E. Mechanisms involved in the selective transfer of long chain polyunsaturated fatty acids to the fetus. Front Genet. 2011;2:57.

52. Bove I, Mardones Santander F, Klaps L, Domínguez de Landa A. Asociaciones entre el crecimiento prenatal y la antropometría materna en el Uruguay. Nutr Hosp. 2014;30(3):643-9.

53. Mary B, Jane W, Kliegman R, Stanton B, Geme J. Nelson Textbook of Pediatrics. 2015.

54. dos Prazeres Tavares H, Arantes MA, Tavares SBMP, Abbade JF, dos Santos DCDM, Calderon IdMP, et al. Metabolic Syndrome and Pregnancy, Its Prevalence, Obstetrical and Newborns Complications. Open J Obstet Gynecol. 2015;5(11):618.

55. Hod M, Yogev Y. Goals of metabolic management of gestational diabetes. Diabetes Care. 2007;30(Supplement 2):S180-S7.

56. Ryckman K, Spracklen C, Smith C, Robinson J, Saftlas A. Maternal lipid levels during pregnancy and gestational diabetes: a systematic review and meta-analysis. Int. J. Gynecol. Obstet. 2015;122(5):64351. 